\title{
V. Experiments on the alloys of steel, made with a view to its improvement
}

\section{J. Stodart Esq. \& M. Faraday}

To cite this article: J. Stodart Esq. \& M. Faraday (1820) V. Experiments on the alloys of steel, made with a view to its improvement, Philosophical Magazine Series 1, 56:267, 26-35, DOI: $10.1080 / 14786442008652361$

To link to this article: http://dx.doi.org/10.1080/14786442008652361

曲 Published online: 29 Jul 2009.

Submit your article to this journal $₫$

山 Article views: 13

Q View related articles ¿ 
V. Experiments on the Alloys of Steel, made with a View to its Improvement. By J. STODART, Esq., and M. FARADAX, Chem. Assistant at the Royal Institution.

I IN proposing a series of experiments on the allors of iron and steel, with various other metals, the object in yiew was two-fold; first, to ascertann whether any alloy could be artificially formed, better for the purpose of making cutting-instruments than sted in its purest state; and, secondly, whether any such alloys would, under similar circumstances, prove less susceptible of oxidation; - new metallic combinations for reflecting mirrors were also a collateral object of research.

Such a series of experiments were not commenced without anticipating considerable difficulties; but the facilities afforded us in the laboratory of the Royal Institution, where they were made, have obviated many of them. The subject was new, and opened into a large and interesting field. Almost an infinity of different metallic combinations may be made according to the nature and relative proportions of the metals capable of being alloyed. It never has been shown by experiment, whether pure iron, when combined with a minute portion ot carbon, constitutes the very best material for making edge tools; or whether any additional ingredient, such as the earths, or thejr bases, or any other metallie matter, may not be advantageously combined with the steel ; and, if so, what the materials are, and what the proportion required to form the best alloy for this much desired and most important purpose. This is confessedly a subject of difficulty, requiring both time and patient investigation, and it will perhaps be admitted as some apology for the very limited progress as yet made.

In analysing wootz, or Indian steel, only a minute portion of the earths alumine and silex is detected, these earths (or their bases) giving to the wootz its peculiar character. Being satisfied as to the constituent parts of this excellent steel, it was proposed to attempt making such a combination, and, with this view, various experiments were made. Many of them were fruitless: the successful method was the following. Pure steel in small pieces, and in some instances good iron, being mixed with charcoal powder were heated intensely for a long time; in this way they formed carburets, which possesșed a very dark metallic grey colour, something in appearance like the black ore of telJurium, and highly crystalline. When broken, the facets of small buttons, not weighing more than 500 grains, were frequently above the eighth of an inch in width. The results of several ex- 
periments on its composition, which appeared very uniform, gave 94.36 iron, $+5 \cdot 64$ carbon. This being broken and rubbed to powder in a mortar, was mixed with pure alumine, and the whole intensely heated in a close crucible for a considerable time. On being removed from the furnace, and opened, an alloy was obtained of a white colour, a close granular texture, and very brittle: this, when analysed, gave 6.4 per cent. alumine, and a portion of carbon not accurately estimated. 700 of good steel, with 40 of the alumine alloy, were fused together, and formed a very good button, perfectly malleable; this, on being forged into a little bar, and the surface polished, gave, on the application of dilute sulphuric acid, the beautiful damask which will presently be noticed as belonging peculiarly to wootz. A second experiment was made with 500 grains of the same steel, and 67 of the alumine alloy, and this also proved good; it forged well, and gave the damask. This specimen has all the appreciable characters of the best Bombay wootz.

We have ascertained, by direct experiment, that the wootz, although repeatedly fused, retains the peculiar property of presenting a damasked surface, when forged, polished, and acted upon by dilute acid. This appearance is apparently produced by a dissection of the crystals by the acid; for though by the hammering the crystals have been bent about, yet their forms may be readily traced through the curyes which the twisting and hatnmering have produced. From this uniform appearance on the surface of wootz, it is highly probable, that the muchadmired sabres of Damascus are made from this steel; and, if this be admitted, there can be little reason to doubt, that the damask itself is merely an exhibition of crystallization. That on wootz it cannot be the effect of the mechanical mixture of two substances, as iron and steel, unequally acted upon by acid, is shown by the circumstance of its admitting re-fusion without losing this property. It is certainly true, that a damasked surface may be produced by welding together wires of iron and steel; but if these welded specimens are fused, the damask does not again appear. Snpposing that the damasked surface is dependant on the development of a crystalline structure, then the superiority of wootz in showing the effect, may fairly be considered as dependant on its power of crystallizing, when sohdifying, in a more marked manner, and in more decided forms than the common steel. - This can only be accounted for by some difference in the composition of the two bodies; and as it has been stated that only the earths in small quantities can be detected, it is reasonable to infer, that the bases of these earths being combined with the iron and carbon render the mass more crystallizable, and that the structure drawn out by the hammer, and confused, 
(though not destroyed,) does actually occasion the damask. It is highly probable, that the wootz is steel accidentally combined with the metal of the earths; and the irregularity observed in different cakes, and even in the same cake, is in accordance with this opinion. The earths may be in the ore, or they may be derived from the crucible in which the fusion is made.

In making the alumine alloy for the imitation of wootz, we had occasion to observe the artificial formation of plumbago. Some of the carburet of iron before mentioned having been pounded and mixed with fresh charcoal, and then fused, was found to have been converted into perfect plumbago. This had not taken place throughout the whole mass; the metal had soon melted, and run to the bottom; but having been continued in the furnace for a considerable time, the surface of the button had received an additional portion of eharcoal, and had become plumbago. It was soft, sectile, bright, stained paper, and had every other character of that body: it was indeed in no way distinguishable from it. The internal part of these plumbago buttons was a crystalline carburet : a portion of it having been powdered, and fused several times with charcoal, at last refused to melt, and on the uncombined charcoal being burnt away by a low heat, it was found that the whole of the steel had been converted into plumbago: this powder we attempted to fuse, but were not successful.

It will appear by the following experiment, that we had formed artificial wootz, at a time when this certainly was not the object of research. In an attempt to reduce titanium, and combine it with steel, a portion of menachanite was heated with charcoal, and a fused button obtained. A part of this button was next fused with some good steel; the proportions were 96 steel, four menachanite button. An alloy was formed, which worked well under the hammer; and the little bai obtained was evidently different from, and certainly superior to, steel. This was attributed to the presence of titanium, but none could be found in it; nor indeed was any found even in the menachanite button itself. The product was iron and carbon, combined with the earths or ther bases, and was in fact excellent wootz. A beautiful damask was produced on this specimen by the action of dilute acid. Since this, manv attempts have been made to reduce the oxide of titan:um; it has been heated intensely with charcoal, oil, \&c., but hitherto all have failed, the oxide has been changed into a black powder, but not fused. When some of the oxide was mixed with steel filings, and a little charcoal added, on being intensely heated the steel fused, and ran into a fine globule which was covered by a dark-coloured transparent glass, adhering to the sides of the crucible. The steel contained no titanium, 
the glass proved to be oxide of titanium, with a little oxide of iron. These experiments have led us to doubt whether titanium has ever been reduced to the metallic state. From the effects of the heat upon the crucibles, which became soft, and almost fluid, sometimes, in fifteen minutes, we had in fact no reason to suppose the degree of heat inferior to any before obtained by a furnace:-that used in these last experiments, was a blast.furnace, supplied by a constant and powerful stream of air; the fuel good Staffordshire coke, with a little charcoal; both Hessian and Cornish crucibles were used, one being carefully luted into another,-and even three have been united, but they could not be made to stand the intense heat.

Meteoric iron is, by analysis, always found to contain nickel. The proportions are various, in the specimens that have been ehemically examined. The iron from the Arctic regions was found to contain three per cent. only of nickel, while that from Siberia gave nearly 10 per cent. With the analysis of this last we are favoured by J. G. Children, Esq., and, having permission from that gentleman, we most willingly insert the account of his very accurate process.

Thirty-seven grains of Siberian meteoric iron gave $48 \cdot 27$ grains of peroxide of iron, and 4.52 grains of oxide of nickel. Supposing the equivalent number for nickel to be 28 , these quan$\begin{array}{llr}\text { tities are equal to } \quad \text { Iron } & 33 \cdot 69 \\ & \text { Nickel } & 3 \cdot 56\end{array}$

$37 \cdot 25$

Supposing the quantities to be correctly

\begin{tabular}{lr} 
Iron & $\begin{array}{r}33 \cdot 5 \\
\text { Nickel }\end{array}$ \\
& $3 \cdot 5$ \\
\hline & $37 \cdot$
\end{tabular}

the proportions per cent. are

$$
\begin{array}{lr}
\text { Iron } & 90: 54 \\
\text { Nickel } & 9 \cdot 46 \\
& 100 \cdot 00
\end{array}
$$

A second experiment, on 47 grains, gave 61 grains of peroxide of iron $=42.57$ iron. The ammoniacal solution of nickel was lost by an accident; reckoning from the iron, the quantities per cent. are,

$$
\begin{array}{lr}
\text { Iron } & \begin{array}{r}
90.57 \\
\text { Nickel } \\
9.42
\end{array} \\
\cline { 2 - 2 } & 99.99
\end{array}
$$

A third experiment, on 56 grains, gave 73.06 grains peroxide 
of iron $=50.99$ iron, and 5.4 of oxide of niekel $=4.51$ nickel, or per cent,

$\begin{array}{lr}\text { Iron } & \begin{array}{r}91 \cdot 00 \\ \text { Nickel }\end{array} \\ \text { Loss } & 099 \\ & \quad 10000\end{array}$

The mean of the three gives. 8.96 per oent. of rickel.

The meteoric iron was dissolved in aqua regia, and the iron thrown down by pure ammonia, well washed, anil heated red.

In the first experiment the ammoniacal solution was evaporated to dryness, the ammonia driven off by heat, and the oxide of nickel re-dissolved in nitric acid, and precipitated by pure potassa, the mixture being boiled a few seconds.

In the third experiment the niekel was thrown down from the ammoniacal solution at once by pure potassa. The first method is best, for a minute portion of oxide of nickel escaped ptecipitation in the last experiment, to which the loss is probably to be attributed.

All the precipitates were heated to redness. J. G. C.

We attempted to make imitations of the nreteoric irons with perfect success. To some good iron (horseshoe nails) were added three per cent. of pure nickel; these were inclosed in a crucible, and exposed to a high tenperature in the air-furnace for some hours. The metals were fused, and on examining the button, the nickel was foutid in combination with the iron. The alloy was taken to the forge, and proved under the hammer to be quite as malleable and pleasant to work as pure iron; the colour when polished rather whiter. This specimen, together/with a small bar of meteoric iron, have been exposed to a moist atmosphere; they are both a little rusted. In this case it was omitted to expose a piece of pure iron with them; it is probable that, under these circumstances, the pure iron would have been more acted upon.

The same success attended in making the alloy to imitate the Stberian meteoric iron agreeably to $\mathrm{Mr}$. Children's analysis. We fused some of the same good iron, with 10 per cent. nickel; the metals were found perfectly combined, but less malleable, being disposed to crack under the hammer. The colour when polished had a yellow tinge. A piece of this alloy has been exposed to moist air for a considerable time, together with a piece of pure iron; they are both alittle rusted, not, hawever, to the same extent ; that with the nickel being but slightly acted upon, comparatively to the action on the pure iron; it thus appears that nickel, when combined with iron, has some effect in preventing 
oxidation, though certainly not to the extent that has at times been given to it. It is a curious fact, that the same quantity of the nickel alloyed with steel, instead of preventing its rusting, appeared to accelerate it very rapidly.

Platimum and rhodium have, in the course of these experiments, been alloyed with iron, but these compounds do not appear to possess any very interesting properties. With gold we have not made the experiment. The alloys of other metals with iron, as far as our experience goes, do not promise much useful, ness. The results are very different when steel is psed; it is only, however, of a few of its compounds that we are prepared to give any account.

Together with some others of the metals, the following have been alloyed with both English and Indian steel, and in various proportions; platinum, rhodium, gold, silver, nickel, copper and tin.

All the above-named metals appear to have an affinity for steel sufficiently strong to make them combine; alloys of platinum, rhodium, gold and nickel, may be obtained when the heat is sufficiently high. This is so remarkable with platinum, that it will fuse when in contact with steel, at a heat at whicl the steel itself is not affected.

With respect to the alloy of silver, there are some very curious circumstances attending it, If steel and silver be kept in fusion together for a length of time, an alloy is obtained, which appears to be very perfect while the metals are in the fluid state, but on solidifying and cooling, globules of pure silver are expressed from the mass, and appear on the surface of the button. If an alloy of this kind be forged into a bar, and then dissected by the action of dilute sulphuric acid, the silver appears, not in combination with the steel, but in threads throughout the masæ; so that the whole has the appearance of a bundle of fibres of silver and steel, as if they had been united by welding. The appearance of these silver fibres is very beautiful; they are sometimes oneeighth of an inch in length, and suggest the idea of giving mechanical toughness to steel, where a very perfect edge may not be required.

At other times, when silver and steel have been very long in a state of perfect fusion, the sides of the crucible, and frequently the top also, are covered with a fine and beautifgl dew of minute globules of silver; this effect can be produced at pleasure. At first we were not successful in detecting silver by chemical tests in these buttons; and finding the steel uniformly improved, were disposed to attribute its excellence to an effect of the silver, or to a quantity too small to be tested. By subsequent experiments 
we were, bowever, able to detect the silver, even to less than one in 500 .

In making the silver alloys, the proportion first tried was one silver to 160 steel; the resulting buttons were uniformly steel and silver in fibres, the silver being likewise given out in globules during solidifying, and adhering to the surface of the fused button; some of these when forged gave out more globules of silver. In this state of mechanical mixture the little bars, when exposed to a moist atmosphere, evidently produced voltaic action, and to this we are disposed to attribute the rapid destruction of the metal by oxidation, no such destructive action taking place when the two metals are chemically combined. These results indicated the necessity of diminishing the quantity of silver, and one silver to 200 steel was tried. Here, again, were fibres and globules in abundance; with 1 to 300 , the fibres diminished but still were present; they were detected even when the.proportion of 1 to 400 was used. The successful experiment remains to be named. When 1 of silver to 500 steel were properly fused, a very perfect button was produced ; no silver appeared on its surface; when forged and dissected by an acid, no fibres were seen, although examined by a high magnifying power. The specimen forged remarkably well, although very hard; it had in every respect the most favourable appearance. By a delicate test every part of the bar gave silver. This alloy is decidedly superior to the very best steel, and this excellence is unquestionably owing to combination with a minute portion of silver. It has been repeatedly made, and always with equal success. Various cutting tools have been made from it of the best quality. This alloy is perhaps only inferior to that of steel with rhodium, and it may be procured at a small expense ; the value of silver, where the proportion is so small, is not worth naming; it will probably be applied to many important purposes in the arts. An attempt was made to procure the alloy of steel with silver by cementation; a small piece of steel wrapped in silver leaf, being 1 to 160 , was put into a crucible, which being filled up with pounded green glass, was submitted to a heat sufficient to fuse the silver; it was kept at a white heat for three hours. On examining it, the silver was fbund fused, and adhering to the steel; no part had combined. The steel had suffered by being so long kept at a high temperature. Although this experiment failed in effecting the alloy of steel with silver, there is reason to believe that with some other metals, alloys may be obtained by this process; the following circumstance favours this suggestion. Wires of platinum and steel, of about equal diameter, were packed together, and, by an expert workman, were perfectly united by welding. This was 
effected with the same facility as could have been done with steel and iron. On being forged, the surface polished, and the steel slightly acted on by an acid, a very novel and beautiful surface appeared, the steel and platinum forming dark and white clouds: if this can be effected with very fine wires, a damasked surface will be obtained, of exquisite beauty. This experiment, made to ascertain the welding property of platinum, is only named here in consequence of observing that some of the largest of the steel clouds had much the appearance of being alloyed with a portion of the platinum. A more correct survey of the surface, by a high magnifying power, went far to confirm this curious fact; some more direct experiments are proposed to be made on this apparent alloy by cementation.

The alloys of steel with platinum, when both are in a state of fusion, are very perfect, in every proportion that has been tried. Equal parts by weight form a beautiful alloy, which takes a fine polish, and does not tarnish; the colour is the finest imaginable for a mirror. The specific gravity of this beautiful compound is 9.862 .

Ninety of platinum with 20 of steel gave also a perfect alloy, which has no disposition to tarnish, the specific gravity $15 \cdot 88$ ? both these buttons are malleable, but have not yet been applied to any specific purpose.

Ten of platinum to 80 of steel formed an excellent alloy. This was ground and very highly polished to be tried as a mirror; a fine damask, however, renders it quite unfit for that purpose.

The proportions of platinum that appear to improve steel for edge instruments; are from 1 to 3 per cent. Experience does not yet enable us to state the exact proportion that forms the best possible alloy of these metals; 1.5 per cent. will probably be very nearly right. At the time of combining 10 of platinum with 80 steel, with a view to a mirror, the same proportions were tried with nickel and steel; this too had the damask, and consequently was unfit for its intention. It is curious to observe the difference between these two alloys, as to susceptibility for oxygen. The platinum and steel, after laying many months, had not a spot on its surface, while that with nickel was covered with rust; they were in every respect left under similar circumstances. This is given as an instance, showing that nickel with steel is much more subject to oxidation than when combined with iron.

The alloys of steel with rhodium are likely to prove highly valuable. The scarcity of that metal must, however, operate against its introrluction to any. great extent. It is to Dr. Wollaston we are indebted, not only for suggesting the trial of "rho. dium, but also for a liberal' supply of the metal, as well as much
Vol. 56. No. 267. July 1820.
E valuable 
valuable information retative to fuel, crucibles, \&c.: this libera lity enables us to continue our experiments on this alloy: these, with whatever else may be worth communicating, will be given in a future of number of this Journal. The proportions we have used are from 1 to 2 per cent. The valuable properties of the rhodium alloys are hardness, with sufficient tenacity to prevent cracking either in forging or in hardening. This superior hardness is so remarkable, that in tempering a few cutting articles made from the alloy, they required to be heated full $30^{\circ} \mathrm{F}$. higher than the best wootz, wootz itself requiring to be heated full $40^{\circ}$ above the best English cast steel. Thermometrical degrees are named, that being the only accurate method of tempering steel.

Gold forms a good alloy with steel. Experience does not yet enable us to speak of its properties. It certainly does not promise to be of the same value as the alloys of silver, platinum, and rhodium.

Steel with two per cent. of copper forms an alloy. Steel also alloys with tin. Of the value of these we have doubts. If, on further trial, they, together with other combinations requiring more time than we have been able to bestow on them, should prove at all likely to be interesting and useful, the results will be frankly communicated.

Our experiments have hitherto been confined to small quantities of the metals, seldom exceeding 2000 grains in weight; and we are aware that the operations of the laboratory are not always successful when practised on a large seale. There does not, however, appear to be any good reason why equal success may not attend the working on larger masses of the metals, provided the same diligence and means are employed.

From the facility of obtaining silver, it is probable that its alloy with steel is the most valuable of those we have made. To enumerate its applications, would be to name almost every edgetool. It is also probable that it will prove valuable for making dies, especially when combined with the best Indian steel. Trial will soon be made with the silver in the large way, and the result, whatever it may be, will be candidly stated.

\section{Talle of Specific Gravities of Alloys, $\mathscr{E}^{\circ} \mathrm{c}$. mentioned in the preceding Paper.

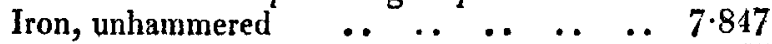

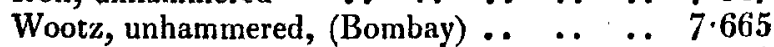

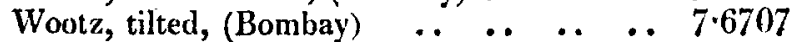 \\ Wootz, in cake, (Bengal) .. \\ Wootz, fused and hammered, (Bengal) .. 7·787


Meteoric iron, hammered .. .. . . . . $7 \cdot 965$ Iron, and 3 per cent. nickel $\quad . . \quad \ldots \quad . .77804$ Iron, and 10 per cent. nickel $\quad \ldots \quad \ldots \quad \ldots 7 \cdot 849$ Steel, and 10 per cent. platinum, (mirror) .. $8 \cdot 100$ Steel, and 10 per cent. nickel, (mirror) .. 7.684 Steel, and 1 per cent. gold, hammered $\quad \because 7.870$ Steel, and 2 per cent. silver, hammered .. $7 \cdot 808$ Steel, and 1.5 per cent. platinum, hammered 7.732 Steel, and 1.5 per cent. rhodium, hammered $7 \cdot 795$ Steel, and 3 per cent. nickel, hammered $\ldots 7 \cdot 750$ Platinum b0, and steel 50, unhammered $*$.. 9.862 Platinum 90 , and steel 20 , unhammered $\dagger \ldots 15 \cdot 88$ Platinum, hammered and rolled ... .. . . 21 25

(Quarterly Journal of Literature, \&̊c.)

* The calculated mean specifie gravity of this alloy is 11.2723 , assuming the specific gravity of platinum and steel as expressed in this table.

+ The calculated mean specific gravity of this alloy is 16.0766 .

VI. Tables of the Sun's Altitude and Zenith Distance, for every Day in the Year, when it passes the Meridian, in Latitude $51^{\circ} 29^{\prime} 8^{\prime \prime}$. By the Rev, Mr. L. Evans.

\title{
To Mr. Tilloch.
}

Sir, $-A_{\text {s every auxiliary is useful to the amateur of practical }}$ astronomy, I have thought the annexed Tables would not be an unacceptable article, in your valualle publication, The Philosophical Magazine, should you have the goodness to insert it. They were computed for the latitude of my Observatory, on Woolwich Common, and are applicable to other latitudes not considerably differing from it.

$$
\begin{aligned}
& \text { I remain, sir, } \\
& \text { Yourr obliged humble servant, }
\end{aligned}
$$

\author{
Woolwich Common, \\ L. Evans. \\ July 19,1820 .
}

The first column, in the Tables, contains the days of the month; the second, the sun's meridian altitudes; and the third, the sun's zenith distances. 